\title{
Las importaciones de literaturas en castellano en Francia desde 1945. Crecimiento del Catálogo Literatura de las Ediciones Seuil y diversidad editorial
}

\section{Les importations des litteratures hispanophones en France depuis 1945. Croissance du catalogue litteraire des Éditions du Seuil et diversité éditoriale}

\section{Hervé Serry}

Director de investigaciones del Centre National de Recheche Scientifique CRESSPA, equipo CSU, UMR 7217, CNRS - Universidad París 8 herve.serry@csu.cnrs.fr

\begin{abstract}
Resumen
Para las ediciones Seuil, relanzadas con fuerza tras la Segunda Guerra Mundial, la publicación de traducciones de obras literarias de diversos orígenes fue decisiva para legitimarse en el campo editorial francés e internacional. El autor de este artículo busca, a partir del análisis del catálogo, seguir la evolución de un sector editorial particular y evaluar los vínculos existentes entre el catálogo y la evolución estructural de la editorial. Se analiza la cantidad de obras traducidas, la distribución de títulos y autores por lengua y, en particular, en el caso de obras provenientes de Hispanoamérica y España, el flujo y la diversidad de las obras traducidas.
\end{abstract}

Palabras Clave: Ediciones de Seuil, literatura latinoamericana y española, traducciones.

\section{Résumé}

Pour les éditons du Seuil, relancées à grande échelle après la Seconde Guerre mondiale, la publication d'œuvres littéraires traduites a été décisive pour conquérir une légitimité dans le champ éditorial français et international. Lauteur de cet article cherche, à travers l'analyse du catalogue, suivre l'évolution d'un secteur particulier de l'édition et évaluer ainsi les liens entre le catalogue et l'évolution structurelle de cette maison d'édition. Il analyse ainsi le nombre d'œuvres traduites, la distribution des titres et des auteurs selon la langue, et en particulier dans le cas des œuvres en provenance d'Amérique latine et d'Espagne, le flux et la diversité des œuvres traduites. 
Mots Clés: Ëditions du Seuil, littérature latino-américaine et espagnole, traductions.

Para la casa editorial Seuil, fundada en París en 1935, y refundada a gran escala después de la Segunda Guerra mundial en 1945, la publicación de obras literarias traducidas fue decisiva para conquistar legitimidad en campo el editorial francés e internacional (Serry, 2004; Serry, 2012). Desde el punto de vista de sus redes y de su imagen de marca literaria, las carencias de esta nueva editorial fueron difíciles de superar y exigieron varios financiamientos durante el año 1959 y luego 1960. Entre estas inversiones cabe destacar que las más importantes fueron las traducciones. Esta conquista de un capital simbólico, decisivo para ser reconocida como una casa de edición literaria generalista, fue aún más difícil para los gestores de Seuil, que reivindicaban la poderosa identidad católica que estimuló la creación de la editorial. Este catolicismo muy presente en el catálogo hasta los años 60, fue connotado negativamente por el campo intelectual, particularmente por el área de la novela, cuyos actores reivindicaban una libertad de creación susceptible de entrar en contradicción con las exigencias morales del catolicismo ${ }^{1}$.

La estrategia instalada por los dueños de Seuil para imponerse en un universo editorial parisino en plena renovación tras la guerra es múltiple. Uno de los caminos emprendidos pasa por la traducción literaria. En efecto, la contratación de novelistas extranjeros puede ser un medio para acumular capital simbólico para una editorial desprovista de una herencia intelectual reconocida. Crear un catálogo de autores extranjeros es, en efecto, más cómodo que crear un espacio literario francés. El déficit de imagen de una editorial nueva puede ser menos pesado a cargar ante los editores extranjeros o, por lo menos, más fácil de completar. Ciertamente, los costos asociados a la publicación de literatura traducida implican un riesgo financiero importante. Sin embargo, es bien sabido que las obras importadas ya han pasado por una primera selección en su país de origen, antes de someterlas a editores franceses a través de diferentes agentes del circuito de transferencia (editores extranjeros, propietarios de derechos, agentes y agencias literarias, lectores). Una colección de literatura extranjera es, entonces, un medio para conquistar un capital literario y para atraer, además, autores franceses. Esta es la lógica por la que los dueños de Seuil siguieron apostando, desde los años de post-guerra, en el terreno extranjero, sin descuidar, por ello, otras inversiones.

1 Ver Serry, H. (2004). Nacimiento del intelectual católico. París: Ediciones La Découverte. En 1947, después del enriquecedor debate interno, Seuil, rechazó la publicación novelas de Samuel Beckett, impregnadas de una visión del mundo juzgada incompatible con el humanismo cristiano. 
Al seguir las evoluciones de un sector editorial en particular, partiendo de los ritmos específicos del catálogo de una casa editorial, se abre la posibilidad de evaluar los lazos que existen entre la producción que un catálogo enseña y las evoluciones estructurales de la editorial. En esta oportunidad, esbozaremos las líneas gruesas de este análisis. La elaboración de un catálogo - en volumen y desde el punto de vista de la variedad de géneros- es un punto de partida privilegiado para percibir las dificultades específicas de un sello editorial dado, ya que permite relacionarlo con la evolución general de la empresa (Simonin, 1996). Para este tipo de estructura dedicada a la edición literaria generalista, este crecimiento está vinculado a la construcción de una imagen de marca y a sus sucesivos reajustes en el tiempo largo de su historia. El equilibrio económico-simbólico de una línea editorial, particularmente de una línea "literaria”, toma múltiples vías. La identidad de un catálogo exige una gestión dinámica y una actualización permanente para que las creaciones del presente (de acuerdo con las inflexiones estéticas o políticas, las nuevas colecciones o los nuevos sectores abiertos) se integren, por una parte, en la historia que el fondo concentra y, por otra, en las exigencias propias de la viabilidad económica (tal como los administradores de una empresa perciben estas restricciones).

Estas lógicas de transferencia para la acumulación primitiva de capital simbólico, luego de la perpetuación de una imagen de marca, conocen innumerables variaciones, profundamente enraizadas en los recursos profesionales y relacionales que los administradores de cada editorial pueden tener. El catolicismo declarado por Seuil es un elemento clave de su identidad. Su naturaleza evolucionará, al igual que el tamaño de la empresa, la diversidad editorial que es capaz de mostrar, su compromiso político e incluso, la evolución de su personal. Partiendo de algunos elementos de estas mutaciones, tras haber vuelto a las características iniciales de Seuil -que marcan en forma duradera su lugar en el campo editorial- podemos analizar las evoluciones morfológicas de un sub-conjunto editorial -la literatura hispanoamericana- con el propósito de examinar cómo las especificidades de un aparato de producción editorial determinan las opciones que presiden a la importación de obras extranjeras. En el sentido contrario, se trata de observar las formas sucesivas que toman los intercambios culturales internacionales, de los cuales conocemos, por lo demás, la estructura global, que pueden ser vistas bajo el prisma de las singularidades de una empresa editorial (Heilbron, 1999). 


\section{DE UN RECIÉN LLEGADO DESPROVISTO DE CAPITAL SIMBÓLICO A LA CONQUISTA DEL PRESTIGIO A TRAVÉS DE LA TRADUCCIÓN LITERARIA}

La editorial Seuil fue fundada en 1935 por un abad católico, Jean Plaquevent. Con recursos modestos y algunos discípulos, este religioso se lanzó en la edición para, según sus propias palabras, "rehacer una Francia cristiana y nacional"2. La pequeña empresa fue continuada, en 1937, por dos cercanos a Plaquevent, Jean Bardet y Paul Flamand. Dotados de una fuerte ambición y de una intensa voluntad de participar en los debates intelectuales de ese tiempo; estos dos administradores y propietarios desean construir una "gran" editorial generalista. Ambos originarios de una burguesía de provincia, pertenecen a fracciones de clase para las cuales la cultura es secundaria. Ellos descubren la literatura (luego el oficio de editor) como autodidactas. Al momento de la Liberación, han publicado al menos una veintena de títulos, pero alcanzaron un éxito en librerías en el medio de los scouts católicos, lo que les permitió iniciar el financiamiento de un verdadero catálogo, especialmente literario. A partir de 1945, los administradores impulsan su empresa en varias etapas importantes de su desarrollo. La despliegan a partir de sus raíces católicas y militantes y tratan de ampliar tanto su oferta como su círculo de influencia. Así, crearon colecciones de vulgarización dirigidas a "todo público" en formato de "libro de bolsillo" destinadas a crear las bases de un fondo editorial rentable. El sector religioso concentra bastantes esfuerzos y, al término de la década de 1960, representó entre el 15\% y el 20\% de la producción. Los ensayos políticos, que comienzan a ser editados gracias a la estrecha colaboración que une Seuil con la revista intelectual del filósofo católico Emmanuel Mounier, Esprit, colocan a la editorial en el centro de los debates de su tiempo. En relación a la novela "francesa", ya lo hemos dicho, los primeros pasos de Seuil fueron difíciles y los resultados muy variables. La contratación de Jean Cayron, un joven autor identificado con la vanguardia, es un paso decisivo. Ello fue posible por el acercamiento producido en 1946 con el sello de su descubridor, los prestigiosos Cahiers du Rhône (Cuadernos del Ródano) fundados por Albert Béguin. Pero, si Cayrol es un punto de apoyo muy pronto indispensable para el desarrollo "literario" en Seuil, su aura y sus intuiciones solo producen sus frutos muy lentamente (Serry, 2009). El catálogo de novelas "francesas" y el de las traducciones literarias se desenvuelven simultáneamente. Los éxitos de Seuil, en el segundo ámbito son más precoces y más estructurantes. El examen de la literatura traducida que se publica bajo este sello revela un conjunto que constituye un sistema y del cual es preciso presentar las grandes líneas, sin entrar en los detalles expuestos en otra parte (Serry 2002). Al considerar los resultados a

2 Para una presentación de la historia de este editor ver Serry, H. (2008). Les Editions du Seuil 70 ansd'édition, Paris: Seuil, Imec. 
largo plazo (de 1946 a 1999)33 , el numero de traducciones literarias (sin distinción de género) publicadas por Seuil en los cinco conjuntos lingüísticos más visibles, se observa una fuerte presencia del conjunto anglo-americano. Otra subdivisión deja ver un peso similar para las traducciones del inglés estadounidense y del alemán ${ }^{4}$. Los títulos provenientes de lenguas hispanoamericanas y del italiano representan alrededor de un $15 \%$ del conjunto.

TABLA 1. Obras traducidas por Ediciones du Seuil (1946 - 1999)

\begin{tabular}{|l|l|l|l|l|l|}
\hline & $\begin{array}{l}\text { Del inglés } \\
\text { estadounidense }\end{array}$ & Del alemán & $\begin{array}{l}\text { Del } \\
\text { español }\end{array}$ & Del italiano & Del inglés \\
\hline $\begin{array}{l}\text { Cantidad de } \\
\text { traducciones } \\
\text { publicadas }\end{array}$ & 146 & 140 & 108 & 104 & 96 \\
\hline
\end{tabular}

Esta forma de organizar los datos esconde, sin embargo, un movimiento general que reencontraremos de acuerdo a ciertas especificaciones para la literatura latinoamericana. En efecto, el espacio alemán es ampliamente mayoritario para los años 1950 y 1960, fase de construcción del catálogo de las ediciones Seuil y su imagen de marca. Durante esta secuencia, lo que duplica el peso simbólico de esta literatura en el catálogo, el seguimiento de los autores germanos es más constante que el de los escritores de otras lenguas: su número es relativamente débil y en promedio Seuil publica más títulos de autores alemanes que de autores anglosajones (Tabla 2). Más adelante, la institucionalización de la editorial -en base al reconocimiento adquirido, de la normalización de una producción presente en todos los sectores y de una identidad intelectual más variada - se manifiesta por el lugar creciente de la literatura americana anclada en un círculo de legitimación más comercial.

3 Los antecedentes utilizados en este artículo necesitan ser revisados. Emanan de diversas fuentes, todas incompletas y todavía insuficientemente revisadas. Las cifras entregadas y los porcentajes calculados son susceptibles de ser precisados. Es lo que explica también que los límites cronológicos sean diferentes según los momentos de análisis.

4 Además de las cinco lenguas más representadas, el catálogo está compuesto por otros veinte idiomas que, para los llegan al menos a 10 publicaciones, el ruso (27 títulos desde 1974); el húngaro (18, desde 1957); el griego (15, desde 1957); el holandés (11, desde 1964) y el japonés (11, desde 1990). Para el mismo período, otras lenguas son el árabe, el polaco, el rumano (8 títulos cada una); el brasilero, el portugués, el serbio-croata (7); el checo (6), el hebreo (5), el danés (4), el chimo y el turco (3), el catalán (2) y una obra para el armenio, el bengalí y el finés. El período más contemporáneo confirmaría una tendencia a esta diseminación lingüística caracterizada por mayor cantidad de lenguas. 
TABLA 2. Distribución de títulos y autores según la lengua (1946-1999)

\begin{tabular}{|c|c|c|c|c|c|}
\hline $\begin{array}{l}\text { Cantidad } \\
\text { de libros } \\
\text { y autores }\end{array}$ & $\begin{array}{l}\text { Lengua esta- } \\
\text { dounidense }\end{array}$ & $\begin{array}{l}\text { Lengua } \\
\text { alemana }\end{array}$ & $\begin{array}{l}\text { Lenguas } \\
\text { hispanoamé- } \\
\text { ricanas }\end{array}$ & $\begin{array}{l}\text { Lengua } \\
\text { italiana }\end{array}$ & $\begin{array}{l}\text { Lengua } \\
\text { inglesa }\end{array}$ \\
\hline 1 & 39 & 27 & 24 & 22 & 36 \\
\hline 2 & 8 & 6 & 9 & 8 & 15 \\
\hline 3 & 5 & 2 & 5 & 2 & 5 \\
\hline 4 & 2 & 1 & 3 & 2 & 3 \\
\hline 5 a 7 & 5 & 1 & 4 & 2 & 2 \\
\hline 8 a 10 & 3 & 3 & 2 & 1 & 0 \\
\hline + de 10 & $\begin{array}{l}1: \\
\text { John Updike } \\
(11)\end{array}$ & $\begin{array}{l}4: \\
\text { Luise } \\
\text { Rinser } \\
(11), \\
\text { G. Grass } \\
\text { (13), } \\
\text { R. Musil } \\
\text { (16), } \\
\text { H. Böll } \\
\text { (17) }\end{array}$ & 0 & $\begin{array}{l}2: \\
\text { Giovanni } \\
\text { Guareschi } \\
(13), \\
\text { Italo } \\
\text { Calvino } \\
(15)\end{array}$ & 0 \\
\hline
\end{tabular}

\section{Contextos políticos, compromisos y opciones de las traducciones alemanas}

Para explicar esta evolución, que está en la base de las opciones de traducción, hay que señalar que desde los años de la post-guerra, en el contexto de reconstruir Europa, a través de un acuerdo franco-alemán sólido y movilizador para el conjunto del continente -dando vuelta la página del nazismo y del conflicto-, es una línea fuerza del compromiso intelectual de Seuil. Construida, especialmente, sobre el hecho de que algunos medios católicos se comprometieron resueltamente sobre este tema aún sensible al finalizar los años negros. Fortalecidos por esta voluntad, y de una afinidad religiosa y del sentimiento de participar en una vanguardia militante e intelectual - de la que la revista Esprit se siente parte-, Jean Bardet y Paul Flamand se acercan a explorar en los círculos literarios que renacen en la "nueva Alemania”, entre los cuales está el "Grupo 47”. Muy pronto, despliegan medios importantes para contratar escritores emergentes, conocen el éxito con el decano que fue Heinrich Böll, pero 
también con Gunther Grass, Alfred Andersch, Stefan Andres, Manfred Gregor, Perter Härtling, Ingeborg Bachman o de Gerturd Von Lefort convertida al catolicismo. La publicación de estos escritores contemporáneos, de inspiración muy variada y cuyas obras conocerán diversos resultados, se completa por la dedicación a un autor clásico de la literatura en lengua alemana, el escritor austriaco Robert Musil, a menudo considerado como el "Proust alemán” y que, sin embargo, jamás había sido traducido a la lengua francesa L’homme sans qualité (El hombre sin atributos). Esta obra difícil, monumental e inacabada, es un acontecimiento literario en 1958 y distingue a Seuil, cuyos críticos destacan su desinteresado coraje. Al año siguiente, Le tambour (El tambor) de Gunther Grass, coloca a Seuil en el centro de la actualidad literaria. Más adelante, el lugar de las literaturas anglosajonas en el catálogo crece progresivamente hasta hacerse dominantes. Además, el catálogo de Seuil se honra con la importante presencia de dos autores nobelizados de lengua alemana, Böll (1972) y Grass (1999), lo que destaca la dedicación particular de sus orígenes. La publicación del único Premio Nobel atribuido a un autor portugués, José Saramago (1998) y más recientemente, con el autor chino Mo Yann (2011), destacan las lógicas de un catálogo editorial menos atípico.

\section{ACERCA DE LA LITERATURA HISPANOAMERICANA EN LAS EDICIONES DU} SEUIL

Como Seuil no había traducido más que algunos títulos -esencialmente clásicos antiguos en edición bilingüe-, es con La familia de Pascual Duarte de Camilo José Cela que se inaugura, en 1948, el catálogo literario hispano-americano del editor. Aparecida inicialmente en 1942, esta novela es la primera de su autor. Haciendo eco a su inmediato éxito, que irá en aumento a pesar de la censura impuesta a la novela durante un tiempo por el poder franquista, la obra conoce numerosas traducciones: al inglés, alemán e italiano en 1944; portugués al año siguiente y más adelante al francés, al ruso y al búlgaro. Estos fueron parte de una serie de argumentos esgrimidos por Jean Viet, el traductor que propuso el libro a Seuil, con el propósito de justificar su elección y que fueron utilizados en los documentos de promoción que el editor envió a la prensa. Jean Viet, redactor de un órgano especializado en asuntos internacionales, l'Année politique, se pone en contacto con Paul Flamand a través de la revista Esprit, editada por esta editorial. Para presentar al autor, consiguió mostrar extractos de La Familia en ese periódico. Sin embargo, las ventas se muestran lentas y las otras propuestas hechas por Jean Viet serán rechazadas por Seuil. 
En 1953, Emmanuel Roblès crea la colección “Mediterranée”. Nacido en Oran en 1914, hispanista y amigo de Albert Camus, Roblès dice sentirse "tan hijo de Argelia como de Italia, de Grecia y de España” (Groussard, 1965). Autor exitoso, es contratado por Seuil para editar la literatura de los "Sures", para los cuales la casa, atenta a las interrogantes vinculadas a la descolonización, se pretende un lugar de acogida. La notoriedad de esta colección descansa largamente sobre los escritores de África del Norte, tales como Kateb Yacine, Mouloud Feraoun y Mohamed Dib. Las literaturas llamadas "francófonas" dominan la serie con más de dos tercios de las publicaciones. Los escritores originarios de España también están presentes como José Luis Villalonga, autor para gran público que Paul Flamand, amistosamente define como “¡nuestro Hidalgo!”. O también con Con la lengua (Mortauxenchères) de José María Castillo Navarro quien sedujo a Seuil "porque, en ella se encuentran sobre el plan literario ( ... una búsqueda técnica de la cual la literatura española ofrece pocos ejemplos; y en el plan social, una reacción valiente y bastante lúcida contra el régimen franquista”. Los títulos siguientes, propuestos por Castillo Navarro tienen diversas recepciones por los lectores de Seuil: al parecer los diálogos demasiado presentes en uno de ellos (Manos cruzadas sobre el halda) llegarían a molestar a los lectores franceses que prefieren novelas más narrativas. "Mediterranée”, permanece así, en una primera etapa, muy centrada en la actualidad ibérica.

Muy luego, Seuil inicia sus búsquedas sobre el continente hispanoamericano, con el objetivo de alimentar la colección "Cadre Vert”, que reúne lo esencial de la literatura traducida de la editorial. La proximidad geográfica con España facilita los intercambios a pesar de las complicaciones derivadas de la censura franquista. Para alcanzar el mercado hispanoamericano, Seuil se apoya en todos los recursos posibles. A comienzos de los años 60, el editor Michel Chodkievicz subraya las dificultades, relacionadas con la distancia, que obstaculizan los contactos con los editores brasileros. Mientras está negociando con el escritor João Guimarães Rosa para adquirir los derechos de sus novelas -entre ellas Buriti, aparece en 1961 traducida por JeanJacques Vilard-, solicita su opinión para identificar a los jóvenes autores que están emergiendo en Brasil. La dureza de la competencia entre editores franceses, que lleva a que Seuil pierda Grande Sertao de Guimarães Rosa no disminuye su determinación, como tampoco las dificultades para seducir a los lectores: "Cualesquiera que sean las hesitaciones del público francés frente a la literatura sudamericana-de la cual siempre me han ofrecido las pruebas más significativas- no puedo dudar que vuestro nombre se impone al lector de un modo decisivo ( ... $)^{\prime \prime}$.

Esta voluntad perdura y aparece claramente en el momento en que Chodkiewicz defiende resueltamente la necesidad de publicar lo que llegará a ser Gestos (1963),

5 Carta de Michel Chodkievicz à José Guimarães Rosa, 3 juin 1965 (archives Seuil, dossier Guimarães Rosa, Imec). 
novela escrita por el cubano Severo Sarduy (la traducción estuvo a cargo de Henri Sylvestre). Más allá de las cualidades intrínsecas de esta obra, insiste en el "interés estratégico" de una publicación como esta, puesto que confiere a la editorial Seuil un mejor acceso a la literatura joven. La editorial Gallimard, gracias al trabajo de Roger Caillois y la colección "La Croix du Sud" (La Cruz del Sur) lleva una "ventaja irrecuperable en el dominio de los clásicos". Piensa, ciertamente, en escritores tales como Borges, Neruda, Vargas Llosa, Fuentes, Puig, asegurados por Gallimard. La competencia viene también de la editorial de Albin Michel (con otros autores, entre ellos Asturias), en Robert Laffont (con Sener y Bioy Casares), en las "Lettres Nouvelles" (con Cela y Pinera) o también de parte de Grasset (con Mallea). Si las exigencias estéticas de Sarduy hacen muy improbable un éxito comercial, este libro pudo tener un rol determinante: "Con la novela de Sarduy ( ... ), podemos comenzar a abrir un terreno nuevo, sobre el cual la competencia no será en un comienzo. A la larga, esta política será ciertamente rentable”. La aceptación de la obra de Severo Sarduy se revela tanto más decisiva. Su autor fue rápidamente reclutado por Seuil para ocupar el puesto de editor. Sus competencias, en la intersección de los mundos literarios parisinos e hispanoamericanos, su cercanía con los ambientes vanguardistas y la revista Tel quel, que Philippe Sollers dirige en la editorial Seuil, confieren a la casa editora oportunidades nuevas sobre un espacio en pleno desarrollo, en momentos en que ella apuesta con mayor determinación hacia el conjunto del sector de literatura extranjera. Las concepciones estéticas de Sarduy se manifiestan en una obra rica y múltiple, pronto reconocida con el Premio Médicis para extranjeros (con Cobra, 1972). Sus redes de contacto, por otrolado, abren nuevas posibilidades de prospección para Seuil, seguido prontamente por los contratos firmados con escritores cubanos tales como Arenas, Padilla o Lezama Lima, quienes aportan a este catálogo un sello que le es propio.

Los sucesivos intermediarios, de diversas naturalezas -agencia, escritores, editores internos o consejeros, traductores, colegas extranjeros...- que Seuil moviliza permiten evocar las especificidades del mercado hispanoamericano, que no puede ser considerado como un conjunto homogéneo y cuya definición es, además, un desafío. La estructura de los intercambios depende en gran medida de estos intermediarios cuyas acciones se determinan por las formas de los diferentes mercados hispanoamericanos. Por consiguiente, estos necesitarían un análisis contrastado imposible de llevar a cabo en el marco de este artículo. Una clasificación diferenciada que permitiera básicamente considerar en contexto el rol de los intermediaros, al estilo de las agencias literarias, como aquella en Barcelona dirigida por Carmen Balcells, que desde los años 1960, controla una cantidad muy importante

6 Nota interna, [1961 ] (archivos Seuil, carpeta Severo Sarduy, Imec). 
de los derechos de autor de los escritores hispanoamericanos ${ }^{7}$ o de algunos editores ibéricos, cuyo rol es decisivo para importar títulos a Europa y para la exportación de títulos desde España, como de Carlos Barral ${ }^{8}$. Estos aspectos de la circulación internacional, identificados con precisión, serían también útiles para delimitar las fronteras, y sus subdivisiones, del corpus de los títulos hispanoamericanos que habría que considerar, más allá de las debilidades de las bases de datos disponibles y de la dificultad para obtener informaciones objetivas sobre el rol de distintos tipos de intermediarios. Así, según el escritor mexicano, Octavio Paz, "el tema de la literatura hispanoamericana es a la vez uno y múltiple; sus orígenes son oscuros, sus límites imprecisos, su naturaleza cambiante y contradictoria, su fin imprevisible ...." La lengua común, que podría ser la lengua castellana, no es más que un factor posible, ya que "los escritores hispanoamericanos han modificado el castellano y este cambio constituye, precisamente, la literatura hispanoamericana”. Por otra parte, marcar límites entre literaturas nacionales al interior de este conjunto es una dificultad adicional que ha de tenerse en cuenta: "Hay excelentes poetas y novelistas colombianos, nicaragüenses y venezolanos, pero no hay una literatura colombiana, nicaragüense o venezolana” (Paz, 2001, pp. 511-525). Dejaremos de lado también estos elementos, a pesar de su importancia en las prácticas de categorizaciones que efectúan los importadores de literaturas y, por lo tanto, por sus elecciones. Los flujos de un catálogo son una imagen reducida de evoluciones más generales que expresan, bajo el prima de una estrategia editorial específica, los factores culturales, económicos y políticos que pesan sobre la estructura de los intercambios internacionales de bienes culturales (Heilbron, 1999).

\section{FLUJOS Y DIVERSIDADES DE LAS TRADUCCIONES}

Se puede considerar que la fase de construcción del Catálogo de Seuil corresponde al período que va desde los orígenes de la casa editorial hasta fines de los años 1970: la producción global conocía entonces un crecimiento fuerte y sostenido. El número de títulos se triplica en cada decenio. Este crecimiento es acompañado por una estructuración de coleccionesyuna densidad también en aumento desdelaperspectiva de los géneros editoriales. Durante el año 1947 se cuentan unos 45 títulos, publicados bajo el sello Seuil y 180 en 1967. Al término de los 10 años siguientes, el aumento es de un 50\% hasta alcanzar 200 libros publicados en 1977. El progreso se mantiene sin alteraciones hasta los años 1990 en que la cifra llega a los 450 a 500 títulos al inicio de

7 A mediados de los años 1970, algunas fuentes afirman que la agencia Balcells es la representante de más del $75 \%$ de escritores del sector hispanoamericano.

8 Nota interna, 18 noviembre [1959] (archivos Seuil, dossier José Maria Castillo Navarro, Imec). 
este período, luego se aproxima a los 600 títulos anuales, con algunas alzas puntuales y coyunturales (Paz, 2001). Estos aumentos de la oferta se producen en favor de una nueva orientación de Seuil, que apunta a desarrollar considerablemente el aparato de distribución comercial, con el propósito de reforzar la independencia editorial. Las inversiones en el ámbito extranjero, especialmente oneroso y con una rentabilidad económica relativa, como lo hemos señalado, se tornan más irregulares. De 1947 a 1956, se pueden señalar 46 traducciones literarias. El crecimiento es menos nítido durante los 10 años siguientes, en lo que concierne a la producción global, puesto que se publican, aproximadamente, unas 120 traducciones. Aunque la editorial Seuil es reconocida en esta área, como lo testimonia el gran número de premios que recibe (Bouvaist, 1993), desde el punto de vista de la cantidad, se constata que el número de escritores extranjeros de notoriedad es menor, tanto en valor absoluto como en porcentaje.

Para el período completo de 1947 a 2006, se consignan unas 172 obras hispanoamericanas. Primeras ediciones y reediciones, aquí se suman, ya que ambos conjuntos participan en forma igualitaria en la visibilidad de ese espacio. El primer hecho destacable, que exigiría ser ajustado por una revisión de los datos en número de títulos, da cuenta que las inversiones 1989 fueron bajas, ya que más del 90\% de estas traducciones aparecen después de esta fecha. Segundo hecho notable, más del 75\% de las traducciones de obras de autores que venían de España (100 títulos del total hispanoamericano) también son posteriores a 1989. La estructura del flujo de este conjunto se sostiene con las importaciones de libros provenientes de España. Los otros conjuntos hispanoamericanos son minoritarios y más irregulares, cualquiera sea el período considerado.

TABLA 3. Origen de los títulos (ediciones y reediciones) sobre el conjunto durante el período 1947-2006

\begin{tabular}{|l|l|l|l|l|l|l|l|l|l|}
\hline España & Argentina & Cuba & Brasil & Chile & México & Uruguay & Paraguay & Perú & Colombia \\
\hline 100 & 18 & 15 & 10 & 8 & 6 & 6 & 5 & 2 & 2 \\
\hline
\end{tabular}


TABLA 4.Títulos de autores hispanoamericanos y nacionalidad

\begin{tabular}{|c|c|c|c|c|c|c|}
\hline & $\begin{array}{l}+ \text { de } 12 \\
\text { títulos }\end{array}$ & $\begin{array}{l}10 \text { a } 12 \\
\text { títulos }\end{array}$ & $\begin{array}{l}6 \text { a } 9 \\
\text { títulos }\end{array}$ & $\begin{array}{l}4 \text { o } 5 \\
\text { títulos } \\
\end{array}$ & \begin{tabular}{|l}
2 a 3 \\
títulos
\end{tabular} & $\begin{array}{l}1 \\
\text { título }\end{array}$ \\
\hline $\begin{array}{l}\text { España } \\
\text { (29 autores) }\end{array}$ & 1 & 2 & 2 & 3 & 6 & 15 \\
\hline $\begin{array}{l}\text { Argentina } \\
\text { (6 autores) }\end{array}$ & & & & 2 & 1 & 3 \\
\hline $\begin{array}{l}\text { Cuba } \\
\text { ( } 5 \text { autores) }\end{array}$ & & & $\begin{array}{l}1 \\
\text { (Reinaldo- } \\
\text { Arenas) } \\
\end{array}$ & $\begin{array}{l}1 \\
\text { (Sarduy) }\end{array}$ & \begin{tabular}{|l|}
1 \\
(Lezama- \\
Lima) \\
\end{tabular} & 2 \\
\hline $\begin{array}{l}\text { Brasil } \\
\text { (5 autores) }\end{array}$ & & & & \begin{tabular}{|l}
1 \\
(Guimares \\
Rosa) \\
\end{tabular} & 1 & 3 \\
\hline $\begin{array}{l}\text { Chile (3 } \\
\text { autores) } \\
\end{array}$ & & & 1 & & & 2 \\
\hline $\begin{array}{l}\text { México } \\
\text { (3 autores) }\end{array}$ & & & & & 2 & 1 \\
\hline $\begin{array}{l}\text { Uruguay } \\
\text { (3 autores) }\end{array}$ & & & & & $\begin{array}{l}1 \\
\text { (Posadas) } \\
\end{array}$ & 2 \\
\hline $\begin{array}{l}\text { Colombia } \\
\text { (1 autor) }\end{array}$ & & & & & & $\begin{array}{l}2 \\
\text { (García- } \\
\text { Márquez) }\end{array}$ \\
\hline $\begin{array}{l}\text { Perú } \\
\text { (1 autor) }\end{array}$ & & & & & \begin{tabular}{|l}
1 \\
(Bryce- \\
Echenique)
\end{tabular} & \\
\hline $\begin{array}{l}\text { Paraguay } \\
\text { (1 autor) }\end{array}$ & & & & $\begin{array}{l}1 \\
\text { (Roa- } \\
\text { Bastos) } \\
\end{array}$ & & \\
\hline
\end{tabular}

Como vemos en el cuadro anterior, contrariamente a la inversión inicial que Seuil hizo en el ámbito alemán, la dispersión del hispanoamericano es sensible, desde la perspectiva de los autores seguidos. La diversidad del corpus de autores hispanoamericanos se evidencia por la ausencia de algún autor publicado en el mediano y largo plazo. Para el corpus ibérico, cuyo dominio en volumen es aplastante, la dispersión es, por una parte, compensada por la presencia de varios escritores, de los cuales una decena de títulos es publicada por Seuil (Montalbán, Mendoza, Molina, Reverte, Capdevila), por otra parte, es reforzada por la cohabitación de antiguos autores (por ejemplo, una re-traducción de Cervantes), de algunos títulos secundarios de autores prestigiados (como Borges, por ejemplo) y por géneros literarios variados (policial, novela histórica o juvenil). Además, es en el seno del grupo de autores españoles que se constatan los mayores éxitos, tales como los que obtuvieron Muñoz-Molina, Pérez Reverte y Montalbán, a los que nos referiremos más adelante. 
Después de publicar a varios autores en forma relativamente aislada, el "boom de la novela latinoamericana” de los años 1960 y 1970 se percibe en el catálogo de Seuil. Las experiencias intentadas alcanzan a veces el éxito, pero son también a menudo operaciones efímeras. Por ejemplo, tras la firma de García Márquez con Cien años de soledad el año 1968. El escritor colombiano, cuyo libro fue propuesto a Seuil por Carmen Balcells, ya había sido publicado en Francia sin llamar la atención del público ni de la crítica (la editorial Julliard había publicado El coronel no tiene quién le escriba en 1961). Por el contrario, Cien años de soledad es un acontecimiento y las ventas en progresión permitieron a Seuil, al inicio de los años 1970 cuando la moda literaria sudamericana pareció decaer, experimentar un éxito con esta exigente obra. En 1973, el libro es cedido al "Libro de bolsillo" para su venta en formato económico, con un tiraje de varias decenas de miles de ejemplares. Se establece entonces un recapitulativo de los resultados comerciales sumando con España y los países sudamericanos, que muestra que la acogida de la novela de García Márquez constituye una excepción: las ventas se sitúan más bien entre los 1.000 a 2.000 ejemplares en promedio. Agreguemos que, comprender los esfuerzos de Seuil por las literaturas traducidas, requeriría considerar las ventas por derechos al extranjero retenidas con respecto a algunos países europeos, así como la totalidad del continente; incluso, el mundo entero. Es así como, a modo de ejemplo, El mundo alucinante del cubano Reinaldo Arenas, se publica primero traducido al francés (1969), antes que Seuil ceda su explotación a una media docena de países. Esta actividad y las ganancias correspondientes nutren la valorización del sector en su conjunto, más allá de la recepción que obtengan estos libros en Francia. Por otro lado, el interés de algunos editores de Seuil por los movimientos políticos de izquierda que actúan en América del Sur de los cuales Claude Durand difunde los escritos a través de su colección "Combats" iniciada en 1968, es otro aspecto de esta presencia editorial.

En 1979, al jubilar los cofundadores de Seuil, Paul Flamand y Jean Bardet, Michel Chodkiewicz, profesional que desde 1950 trabajaba en la casa editorial, es nombrado para ocupar la dirección de la empresa. Él efectúa una serie de importantes reorganizaciones internas que permitan un crecimiento editorial y económico, cuyo balance de los años 1980 es una prueba del éxito alcanzado. Durante la década siguiente, a solicitud de los accionistas, la estrategia de Claude Cherki, el nuevo Presidente director general nombrado en 1989, consiste en acentuar significativamente este desarrollo en progreso mediante el reforzamiento del aparato industrial de distribución de Seuil. Con un dinamismo sostenido, Cherki prosigue y acelera la racionalización del funcionamiento interno de la editorial. Los circuitos de decisión editorial y la responsabilidad se atribuyen ahora en forma más directa.

Para el sector que nos ocupa, se contrata a una editora especializada, Annie Morvan, quien participa en la reorganización general. Es experta en traducción, en apoyo y comercialización de literatura hispanoamericana. Cabe destacar que ella 
fundó una agencia dedicada a este sector a comienzos de los años 1980, trabajó como responsable del sector en la editorial Actes Sudyluego dirigió, junto con otras personas, las ediciones Trilce, en Montevideo, Uruguay. Trilce, en la que permaneció hasta fines de 1980, tenía como propósitos principales promover a los escritores sudamericanos ante públicos de ese continente, aunque fue más conocida en Europa. Annie Morvan es una traductora de renombre, participó en el Congreso de lanzamiento de la Traducción en Arles, ciudad del sur de Francia. Esta actividad y el dinamismo que provoca se inscriben en una actualidad de la literatura española en Francia e, incluso, más amplia. Dos ediciones del Salón del Libro de París - 1992 y 1995 - honran esta producción. Habría que observar esta realidad contrastándola con la actualidad internacional, la que se manifiesta en toda su amplitud en la Feria de Fráncfort ${ }^{9}$. El auge comercial de Seuil se traduce en una política voluntarista de contratos a escritores cuya visibilidad sea un triunfo para la casa editora, como es el caso de Arturo Pérez Reverte y sus novelas costumbristas. Sus primeros títulos en francés los publica Lattès, luego, en 1994, cambia de editor y va a la editorial Seuil. El arribo más tardío de Antonio Muñoz Molina, al comienzo publicado por Actes Sud, se inscriben en el mismo dinamismo. Esta estrategia implica abrir el catálogo a géneros dominantes, tales como la novela policial, vector de crecimiento comercial después de los años 90 . Michèle Gazier, traductora de Montalbán -escritor español como Reverte y Molina-, recuerda sus dificultades para convencer a los editores parisinos para que publicaran a este escritor que obtuvo, en especial, en Seuil un éxito considerable. Desde este punto de vista, incorporar a autores para la "juventud", tales como Roser Capdevilla y Enric Larreula es también sintomático de una diversificación del catálogo de la editorial (en diversos formatos, doce libros están presentes en la editorial Seuil). Para casi todos, Seuil, impulsada por una dinámica de retomar el formato "de bolsillo", garantiza a esos autores españoles mayores un apoyo promocional destacable. Las evoluciones de la estrategia global de Seuil son importantes para comprender las expectativas de éxito de dichos escritores, ante un público lector amplio y diversificado.

La circulación de literatura hispanoamericana en el seno del catálogo de las ediciones de Seuil está, por consiguiente, ampliamente determinada por la presencia de escritores que provienen del sub-conjunto español, el que refuerza su presencia dominante por el reconocimiento "público" que han logrado los principales autores de España desde los años 90. Para conferir mayor precisión a este estudio habría que retomar los antecedentes, como ya fue señalado. Del mismo modo, sería necesario considerar las características de los escritores, en particular, desde el punto de vista del género literario y de la edad del público lector. Aún más, el lugar en su obra respectiva

9 Ver por ejemplo: Sôra, G. (1996). Os livros do Brasil entre o Rio de Janeiro e Frankfurt. Revista Brasileira de Informação Bibliográfica em Ciências Sociais, 41, 3 - 33. 
de los libros publicados en francés. Esos datos podrían aclarar el análisis que se ha bosquejado aquí, respecto del ámbito hispanoamericano, relativo a la estructuración global del sector extranjero de la editorial Seuil y referida a los años más recientes del crecimiento de la empresa (1990-2000). Se trataría de un intento por examinar cómo el catálogo de las traducciones se diversifica en términos de lenguas seleccionadas y observar si, independientemente, de las lenguas de autores publicados poseen características comunes.

\section{Referencias bibliográficas}

Bouvaist, J. M. (1993). Crise et mutations dans l'édition française. Ministère de la culture, Cahiers de l'Economie du livre, 3, 243-261.

Groussard, S. (1965). Entretien avec Emmanuel Roblès. Livres de France, 2.

Heilbron, J. (1999). Towards à Sociology of Translation: Book Translations as a Cultural World-System. European Journal of Social Theory, 2(4), 429-444.

Paz, O. (2001). Alentours de la littérature hispano-américaine. En Carvallo, F. (Comp.), L'Amérique latine et La Nouvelle revue française. París: Gallimard.

Serry, H. (2002). Constituer un catalogue littéraire. La place des traductions dans l'histoire des Editions du Seuil. Actes de la recherche en sciences sociales, 144, 70-79.

Serry, H. (2004). Nacimiento del intelectual católico. París: Ediciones La Découverte.

Serry, H. (2008). Les Editions du Seuil: 70 ansdédition. Paris: Seuil, Imec.

Serry, H. (2009). Jean Cayrol et Ecrire. L'invention d'un catalogue romanesque. La Revue des revues. Histoire et actualité des revues, automne, 42, 3-19.

Serry, H. (2012). A publishing Decision under Constraints. Samuel Beckett and Le Seuil Publishers in 1947. Journal of Beckett Studies, 21(1), 65-87.

Simonin, A. (1996). Le catalogue de l'éditeur, un outil pour l'histoire. L'exemple des éditions de minuit. Vingtième Siècle. Revue d'histoire, 1(81), 119-129. 